\title{
The relationship between characteristics of root morphology and grain filling in wheat under drought stress
}

\author{
Xinyu Chen ${ }^{1}$, Yu Zhu ${ }^{1}$, Yuan Ding ${ }^{1}$, Rumo Pan ${ }^{1}$, Wenyuan Shen ${ }^{1}$, Xurun Yu ${ }^{1}$, Fei Xiong ${ }^{\text {Corresp. } 1}$ \\ 1 Jiangsu Key Laboratory of Crop Genetics and Physiology/Co-Innovation Center for Modern Production Technology of Grain Crops/Joint International \\ Research Laboratory of Agriculture \& Agri-Product Safety of the Ministry of Education, Yangzhou University, Yangzhou, Jiangsu, China \\ Corresponding Author: Fei Xiong \\ Email address: feixiong@yzu.edu.cn
}

Drought is a common yield limiting factor in wheat production and has become a significant threat to global food security. Root system is the organ responsible for water uptake from soil and root growth is closely associated with yield and quality of wheat. However, the relationship between morphological and structural characteristics of root growth and caryopsis enrichment in wheat under drought stress is unclear. In this study, two wheat cultivars (YM13 and YN19) were treated with drought from flowering to caryopsis maturity stage. The changes in morphological structure of roots and the characteristics of endosperm enrichment were investigated. Drought stress significantly reduced the root length, plant height, root dry weight and aboveground parts dry weight. Whereas the root-shoot ratio of YM13 and YN19 increased by $17.65 \%$ and $8.33 \%$ under drought stress, respectively. The spike length, spike weight, grains number per spike and 1000-grains weight of mature wheat also significantly declined under drought stress. Meanwhile, the cross section structure of roots was changed with the enlargement of vascular cylinder and dense distribution of xylem vessels under drought stress. Additionally, drought stress affected the substance enrichment in wheat caryopses, decreasing starch accumulation and increasing protein accumulation of endosperm. Correlation analysis suggested that the root length was closely correlated with the relative areas of amyloplast $(0.51)$ and protein body $(0.70)$, and drought stress increased the correlation coefficient ( 0.79 and 0.78 , respectively). While the root dry weight had a significantly positive correlation with the plant height and aboveground parts dry weight. The results can provide theoretical basis for root architecture optimization, water-saving and high-yield cultivation and quality improvement in wheat. 


\section{The relationship between characteristics of root}

2 morphology and grain filling in wheat under drought

3 stress

4

5

6

7

8

12

Xinyu Chen, Yu Zhu, Yuan Ding, Rumo Pan, Wenyuan Shen, Xurun Yu, Fei Xiong

Jiangsu Key Laboratory of Crop Genetics and Physiology/Co-Innovation Center for Modern

Production Technology of Grain Crops/Joint International Research Laboratory of Agriculture \& Agri-Product Safety of the Ministry of Education, Yangzhou University, Yangzhou, Jiangsu, China

Corresponding Author:

Fei Xiong

No. 48 Wenhui East Road, Yangzhou, Jiangsu, 225009, China

Email address: feixiong@yzu.edu.cn

\section{Abstract}

Drought is a common yield limiting factor in wheat production and has become a significant threat to global food security. Root system is the organ responsible for water uptake from soil and root growth is closely associated with yield and quality of wheat. However, the relationship between morphological and structural characteristics of root growth and caryopsis enrichment in wheat under drought stress is unclear. In this study, two wheat cultivars (YM13 and YN19) were treated with drought from flowering to caryopsis maturity stage. The changes in morphological structure of roots and the characteristics of endosperm enrichment were investigated. Drought stress significantly reduced the root length, plant height, root dry weight and aboveground parts dry weight. Whereas the root-shoot ratio of YM13 and YN19 increased by $17.65 \%$ and $8.33 \%$ under drought stress, respectively. The spike length, spike weight, grains number per spike and 1000-grains weight of mature wheat also significantly declined under drought stress. Meanwhile, the cross section structure of roots was changed with the enlargement of vascular cylinder and dense distribution of xylem vessels under drought stress. Additionally, drought stress affected the substance enrichment in wheat caryopses, decreasing starch accumulation and increasing protein accumulation of endosperm. Correlation analysis suggested that the root length was closely correlated with the relative areas of amyloplast $(0.51)$ and protein body $(0.70)$, and drought stress increased the correlation coefficient ( 0.79 and 0.78 , respectively). While the root dry weight had a significantly positive correlation with the plant height and aboveground parts dry weight. The results can provide theoretical basis for root architecture optimization, water-saving and highyield cultivation and quality improvement in wheat. 


\section{Introduction}

41 Wheat is the most widely distributed cereal crop in the world with the largest planting area, and it plays an important role in global food production, trade and even food security. Drought stress is one of the important abiotic factors that affects crop growth and limits crop yield. Barnabás,

44

45

46

47

48

49

50

51

52

53

54

55

56

57

58

59

60

61

62

63

64

65

66

67

68

69

70

71

72

73

74

75

76

77

78

79
Jäger \& Fehér (2008) demonstrated that drought stress can affect the yield of cereal crops from morphology, physiology and development. Previous studies showed that drought during wheat flowering and grain filling stages can cause a substantial decrease in yield (Farooq, Hussain \& Siddique, 2014; Morales et al., 2020). While, Yang \& Zhang (2006) found that water deficit during wheat grain filling stage decreased photosynthetic rate and grain filling rate, shortened grain filling time, promoted premature senescence of plants, but increased the metabolism of non-structural carbohydrates from vegetative organs to grains.

Caryopsis is an important organ for storing nutrients in wheat, and its development directly determines the yield and quality of wheat. As the main histological structure, endosperm accounts for more than $85 \%$ of the total weight of wheat caryopses. Starch and protein are the main storage substances of endosperm, which accumulate in endosperm cells in the form of amyloplast and protein body respectively (Moore et al., 2016; Seung \& Smith, 2019).

Predecessors have conducted a lot of researches about the effect of drought stress on the development of wheat caryopses, and found that drought stress caused changes in wheat quality by mainly affecting the accumulation of starch and protein in caryopses (Ahmadi \& Baker, 2001; Ge et al., 2012). Lu et al. (2014) pointed out that the contents of total starch and amylopectin, along with the proportion of B-type amyloplast, in wheat endosperm decreased under drought stress. Meanwhile, drought stress increased the protein content of wheat caryopses, leading to the increase in flour sedimentation value, wet gluten content, dry gluten content, and bread volume (Kimball et al., 2001; Ozturk and Aydin, 2004; Houshmand et al., 2005).

Wheat root system is the main place for water and nutrient absorption. Its morphological and physiological characteristics has a close relationship with the growth and development of wheat aboveground part, especially caryopses, thus affecting the formation of wheat yield and quality (Ober et al., 2021). The absorption of water by wheat roots is not only restricted by physical and mechanical properties of soil, but also affected by root growth and metabolism. In addition, the occurrence, development and physiological changes of root system depend on the moisture status of soil to some extent. Therefore, wheat root system and soil moisture are interdependent and restrict each other. Under drought stress, root number, root length, root specific surface area, root-shoot ratio, root growth potential, root water potential, and diameter of root vessel in wheat all changed significantly (Végh, 1991; Awad et al., 2018). Besides root morphological indexes, drought stress also had corresponding effects on some physiological indicators of roots, such as root bleeding sap, root respiration rate, root plasma membrane permeability, membrane lipid peroxidation level, protective enzymes activity and others (Kaul, 2011).

There are many morphological and physiological studies on wheat root system under drought stress at home and abroad and they are mainly concentrated in germination and seedling

Peer] reviewing PDF | (2021:06:61867:1:1:NEW 11 Jul 2021) 
80

81

82

83

84

85

86

87

88

89

90

91

92

93

94

95

96

97

98

99

100

101

102

103

104

105

106

107

108

109

110

111

112

113

114

115

116

117

118

stages of wheat. However, the researches on root system at later stage of wheat growth (booting stage and filling stage) is very weak. Very little information is available concerning structural characteristics of wheat roots under drought stress and the relationship between root morphology and caryopsis enrichment remains to be elucidated. In this study, Yangmai 13 (YM13) and Yannong 19 (YN19) were used as materials and subjected to drought stress from flowering to caryopsis maturity stage. The changes in morphological and structural characteristics of root and caryopsis development in wheat under drought stress were investigated by morphological observation and resin slicing. The relationship between root morphology and endosperm enrichment was also revealed. The results can not only enrich the cytological research of wheat roots, but also provide theoretical basis for root system architecture optimization, water-saving cultivation and quality improvement of wheat.

\section{Materials \& Methods}

\section{Plant materials and drought treatment}

The wheat cultivars selected in this study were YM13 and YN19, which were provided by the Institute of Agricultural Science of the Lixiahe District in Jiangsu Province. These two wheat cultivars are widely cultivated in the region of Yangtze River with different degrees of response to drought stress. Seeds were sown in plastic pots ( 20 seeds per pot), which were placed in rainproof shelters in the experimental field of Key Laboratory of Crop Genetics and Physiology in Yangzhou University from October 2018 to May 2019. The soil is sandy loam soil with an organic matter content of $2.45 \%$, nitrogen content of $106 \mathrm{mg} / \mathrm{kg}$, phosphorus content of 33.8 $\mathrm{mg} / \mathrm{kg}$, and available potassium content of $66.4 \mathrm{mg} / \mathrm{kg}$. Seedlings were thinned to six plants per pot two weeks after sowing. During flowering period, two individual florets at the base of central ears were marked with a marker pen and the plants were tagged with anthesis date.

Drought treatment was carried out by strictly controlling watering during the stage from flowering to caryopsis maturity referring to previous researches (Yang et al., 2004; Yu et al., 2015). A minupressure soil hygrometer was inserted to measure the water potential at a depth of $20 \mathrm{~cm}$ in the soil. The water potential of control condition and drought stress were controlled at 20 and $-60 \mathrm{kPa}$, respectively. Each treatment group contained 20 pots.

\section{Morphological observation of plants, roots and caryopses}

The soil in the plot was washed with water at 30 days post anthesis (DPA) and the roots were cleaned with an agricultural compression sprayer to observe the morphology by taking photographs. The root length and plant height were also measured. Then, the roots and aboveground parts of the plant were separated and baked in an oven at $42^{\circ} \mathrm{C}$ to constant weight. The dry weight was determined and the root-shoot ratio was calculated. In addition, fresh caryopses at 10,20 and 30 DPA were collected to determine the fresh weight and then dried in the oven at $42^{\circ} \mathrm{C}$ to determine the dry weight. Wheat spikes were harvested at mature stage and the spike length, spike weight, grains number per spike and 1000-grains weight were measured. Six wheat plants were selected as replicates for the above indicators determination.

Histological observation of roots and caryopses 
119 Wheat root and caryopsis samples were collected as previously described in Li et al. (2020). The

120

121

122

123

124

125

126

127

128

129

130

131

132

133

134

135

136

137

138

139

140

141

142

143

144

145

146

147

148

149

150

151

152

153

154

155

156

157

158

root samples were the segments of secondary root which were $2 \mathrm{~cm}$ from the stem axis base and the caryopsis samples selected were in the same position of the middle of main spike. The steps of sample resin slicing and observation referred to the method of Chen et al. (2017). Specifically, the samples were cut transversely into $2 \mathrm{~mm}$ slices from the middle with a razor blade and quickly soaked into $2.5 \%$ glutaraldehyde fixative solution at $4^{\circ} \mathrm{C}$ for $48 \mathrm{~h}$. The fixed samples were subsequently rinsed thrice (10 min each time) with phosphate buffer solution and dehydrated by gradient ethanol, followed by the replacement of propylene oxide. Then, the samples were infiltrated and embedded using Spurr resin and polymerized in an oven at $70^{\circ} \mathrm{C}$ for $12 \mathrm{~h}$. Afterwards, the ultramicrotome (Ultracut R, Leica, Germany) was used to cut the samples into $1 \mu \mathrm{m}$ slices and stained with $0.5 \%$ methyl violet. The slices were observed and photographed under a light microscope (DMLS, Leica, Germany) equipped with a CCD camera (Truechrome II, Truechrome, China). Each treatment contained three replicated samples and each root and caryopsis sample was from different plants of different pots.

\section{Structural characteristics analysis of endosperm enrichment}

Image-Pro Plus 6.0 and Photoshop CC 2017 software were used to analyze the relative areas of amyloplast and protein body in endosperm based on microphotographs, according to the method previously described (Yu et al., 2015; Li et al., 2020). Specifically, the central endosperm region was photographed at 200 times magnification. The amyloplast, protein body and corresponding endosperm cell in the microphotograph were colored using Photoshop and the areas of colored regions were measured using Image-Pro Plus. The areas of amyloplast and protein body respectively divided the area of their corresponding endosperm cells were defined as the relative areas of amyloplast and protein body. Three caryopsis samples from different plants were selected as replicates for each treatment and ten micrographs were analyzed for each sample.

\section{Statistical analysis}

The experimental data were recorded using Microsoft Excel 2016. The significance analysis (Duncan method, $\mathrm{p}<0.05)$ and Pearson correlation coefficient $(\mathrm{p}<0.05)$ were conducted using SPSS 19.0 software. The figures were produced using Photoshop and Origin 9.1 software.

\section{Results}

\section{Plant growth of wheat under drought stress}

The morphological indexes of wheat plants under drought stress are shown in Table 1. Drought stress significantly reduced the plant height of YM13 and the root length, root dry weight and aboveground part dry weight of YM13 and YN19, but had no significant effect on the plant height of YN19. At the same time, YM13 showed higher reduction degree in the root length and plant height under drought stress than YN19. While YN19 showed higher reduction degree in the root dry weight and aboveground parts dry weight than YM13. Under drought stress, the rootshoot ratio of YM13 and YN19 increased by $17.65 \%$ and $8.33 \%$, respectively. In addition, drought stress significantly decreased the spike length, spike weight, grains number per spike, and 1000-grains weight of YM13 and YN19. The range of decrease in the spike length and 1000grains weight was higher in YM13 than that in YN19 (Table 1).

Peer] reviewing PDF | (2021:06:61867:1:1:NEW 11 Jul 2021) 
159 Morphological structure of wheat roots under drought stress

160 The root morphology of wheat in the whole pot was observed and it was found that the root

161 system of YM13 was smaller and shorter while the root system of YN19 did not change

162 significantly under drought stress (Fig. 1A). From the microstructure of root cross section, the

163 cortex, vascular cylinder, vessel, and phloem can be observed. Under drought stress, the area of

164 vascular cylinder became larger and more xylem vessels were differentiated and tightly arranged

165 in the cross section of YM13 roots (Figs. 1B and 1C). However, the structure of root cross

166 section in YN19 did not change significantly under drought stress and there was no significant

167 difference in the area of vascular cylinder and the number of xylem vessels compared with

168 control (Figs. 1D and 1E).

169 Enrichment of wheat caryopses under drought stress

170 The changes in the fresh and dry weight of wheat caryopses under drought stress are shown in

171 Fig. 2. During the development of caryopses, the fresh weight first increased and then decreased,

172 while the dry weight showed a continuous trend of increase. Under drought stress, the fresh

173 weight of caryopses in YM13 and YN19 significantly decreased during the whole development

174 process (Fig. 2A). At 10 DPA, the dry weight of caryopses in YM13 and YN19 did not change

175 significantly under drought stress, while drought stress significantly reduced the dry weight at 20

176 and 30 DPA (Fig. 2B). In addition, YM13 presented greater reduction in the fresh and dry weight

177 of caryopses under drought stress than YN19.

178 Substance accumulation characteristics in wheat endosperm was observed at 10, 20 and 30

179 DPA, and micrographs are shown in Figure 3. At the same time, the relative areas of amyloplast

180 and protein body in endosperm cells were calculated using Image-Pro Plus software (Figs. 2C

181 and 2D). At $10 \mathrm{DPA}$, there is some starch accumulating in endosperm cells and distributing on

182 the edge of cells. For two wheat cultivars, drought stress significantly decreased the

183 accumulation of amyloplast in endosperm and YM13 showed greater decrease than YN19 (Fig.

184 2C, Figs. 3A-D). A small amount of protein body was also observed in endosperm cells, but the

185 change of protein body accumulation under drought stress was not obvious. Moreover, there was

186 no significant difference in the response degree to drought between two wheat cultivars (Fig.

187 2D).

188 At 20 DPA, the endosperm of YM13 was further enriched and the volume and amount of

189 amyloplast increased. The accumulation and aggregation of some small endosperm protein body

190 was also clearly observed in YM13 (Figs. 3E and 3F). Under drought stress, the relative area of

191 amyloplast significantly decreased, while the relative area of protein body significantly increased

192 in YM13 (Figs. 2C and 2D). For YN19, the endosperm was not as full as YM13 and there were

193 large gaps between amyloplast. Some protein aggregations coalesced by small protein body were

194 also observed in endosperm (Figs. 3G and 3H). Meanwhile, drought stress significantly

195 decreased amyloplast accumulation but increased protein body accumulation of endosperm in

196 YN19 (Figs. 2C and 2D). For the relative area of endosperm amyloplast, the reduction degree

197 under drought stress was higher in YM13 than that in YN19 (29.03\% vs. 16.47\%). For the

Peer) reviewing PDF | (2021:06:61867:1:1:NEW 11 Jul 2021) 
198

199

200

201

202

203

204

205

206

207

208

209

210

211

212

213

214

215

216

217

218

219

220

221

222

223

224

225

226

227

228

229

230

231

232

233

234

235

236

237

relative area of endosperm protein body, the augment degree under drought stress was higher in YM13 than that in YN19 (22.88\% vs. 8.96\%).

At 30 DPA, the endosperm of two wheat cultivars was entirely enriched. The amyloplast were squeezed each other and the protein body with enlarged volume accumulated in the gaps of amyloplast (Figs. 3I-L). Drought stress significantly reduced the relative area of endosperm amyloplast and increased the relative area of endosperm protein body in both YM13 and YN19 (Figs. 2C and 2D). However, the decrease of amyloplast accumulation and the increase of protein body accumulation were more responsive to drought stress in YM13 than those in YN19.

The above results showed that drought stress could affect the substance accumulation in wheat caryopses by reducing accumulation starch and increase protein accumulation in endosperm, thus resulting in the decrease of caryopsis weight. However, the impact of drought stress on YM13 was greater than that on YN19.

\section{Relationship of root morphological structure and endosperm enrichment in wheat under drought stress}

In order to investigate the relationship between root morphological structure and endosperm substance accumulation, the correlation analysis of roots and aboveground parts traits was carried out. The root length was negatively correlated with the plant height, aboveground parts dry weight and 1000-grains weight, and positively correlated with the spike weight, relative areas of amyloplast and protein body. The root length had a significantly strong correlation with the plant height and relative area of protein body under control condition, while the root length had a significantly strong correlation with the relative areas of amyloplast and protein body under drought stress. This indicated that drought stress reduced the correlation between the root length and the plant height, and increases the correlation between the root length and the relative area of amyloplast (Table 2). Except for the relative area of protein body, the root dry weight was positively correlated with other aboveground parts traits. Among them, the root dry weight was closely related to the plant height and aboveground parts dry weight with a significance under control and drought stress. However, drought stress reduced the correlation between the root dry weight and 1000-grain weight (Table 2). In addition, the root-shoot ratio was negatively correlated with other traits except the 1000-grains weight. Under control condition, the rootshoot ratio had a significantly strong correlation with the aboveground parts dry weight, spike weight and relative area of amyloplast. While, drought stress decreased correlation coefficients of the root-shoot ratio with the aboveground parts dry weight and spike weight, and enhanced the correlation coefficients of the root-shoot ratio with the relative areas of amyloplast and protein body (Table 2). The above results indicated that the root length was strongly correlated with the relative areas of amyloplast and protein body, and drought stress increased correlation coefficients between them. Meanwhile, the root dry weight had a great correlation with the plant height and aboveground parts dry weight.

\section{Discussion}

The growth of root system is related to the growth period and genotype of plants and is affected by environmental factors such as drought (Rellán-Álvarez, Lobet \& Dinneny, 2016). It is 
238

239

240

241

242

243

244

245

246

247

248

249

250

251

252

253

254

255

256

257

258

259

260

261

262

263

264

265

266

267

268

269

270

271

272

273

274

275

276

277

generally believed that roots absorb water from the soil first to meet the need of its own growth and development. Thus, the damage degree of roots is lighter than that of shoots when exposed to water stress, leading to the increase of root-shoot ratio. Under severe water shortage, the elongation and growth of wheat roots were severely hindered and the dry matter of roots was significantly reduced (Xue et al., 2003). In this study, drought stress decreased the length and dry weight of wheat roots and affected the growth of aboveground parts, resulting in a decline in the plant height and aboveground parts dry weight. Ultimately, the yield of wheat spikes was also decreased. The root vascular bundle is a channel for the transportation of water and inorganic salts, which is essential to cope with water changes even deficits. In this study, the cross section structure of wheat roots was observed and it was found that the area of vascular cylinder was larger with denser distribution of xylem vessels under drought stress. This phenomenon might be related to water flow conductivity. The radial and axial resistance are the main factors affecting the water flow conductivity of the root system (Vadez, 2014). Large vessels will appear the embolism formed by bubbles, thus the radial and axial hydraulic resistance will increase (Niu et al., 2016). Thereby, the root water flow conductivity is reduced and the root water absorption is limited, which is not conducive to plant growth under drought stress (Bartlett et al., 2016). While, the small and narrow xylem vessels could transport water more efficiently, which was similar to the results of previous researches (Thorsten \& Wieland, 2011; Comas et al., 2013).

Wheat roots is the organ that absorbs water and senses environmental changes in the soil. Many root characteristics are related to drought tolerance, such as root depth, angle, density, surface area and xylem diameter. They are all root characteristics that affect drought tolerance of wheat and is closely related to the growth and yield of wheat. Previous studies have investigated the relationship between root architectural traits and yield components in wheat seedling, and it is found that seminal root number and total root length were both positively associated with aboveground biomass, grains per spike, and grain yield (Xie et al., 2017). This is consistent with the results in this study that the root dry weight was highly correlated with the plant height and aboveground parts dry weight. In the study of Li et al. (2019), the root depth of wheat was significantly negatively correlated with canopy temperature and significantly positively correlated with the yield per plant. But the root depth had no significant correlation with the plant height and root dry weight. This reflected the complexity of root architecture, that was the diversity of root dry matter distribution in different soil layers. In present study, the relationship between root growth and caryopsis enrichment in wheat was analyzed, and it was found that the root length had a great correlation with the relative area of amyloplast and protein body and drought stress increased the correlation coefficients between them, which explained the relationship between root development and quality formation in wheat to a certain extent. In general, the root architecture is of great importance to yield, quality and stress tolerance of wheat. Optimizing root architecture and investigating the balance relationship between root morphological structure and aboveground agronomic traits are powerful means to promote variety improvement and improve drought resistance in wheat.

\section{Conclusions}

Peer] reviewing PDF | (2021:06:61867:1:1:NEW 11 Jul 2021) 
278 In this study, the morphological structure of roots and the characteristics of endosperm

279 enrichment in wheat under drought stress were investigated. Drought stress significantly reduced 280 the root length, plant height, root dry weight and aboveground parts dry weight but increased the

281

282

283

284

285

286

287

288

289

290

291

292

293

294

295

296

297

298

299

300

301

302

303

304

305

306

307

308

309

310

311

312

313

314

315

316

317

root-shoot ratio. The spike length, spike weight, grains number per spike and 1000-grains weight of mature wheat also significantly declined under drought stress. Meanwhile, the cross section structure of roots was changed under drought stress with the enlargement of vascular cylinder and dense distribution of xylem vessels. In additional, drought stress affected the substance enrichment in wheat caryopses with a decrease in starch accumulation but an increase in protein accumulation of endosperm. Correlation analysis suggested that the root length was closely correlated with the relative areas of amyloplast and protein body, and drought stress increased the correlation coefficient. While the root dry weight had a significantly positive correlation with the plant height and aboveground parts dry weight. The results can provide insight into root growth and caryopsis development of wheat under drought stress and guide root architecture optimization and quality improvement in wheat.

\section{References}

Ahmadi A, Baker DA. 2001. The effect of water stress on the activities of key regulatory enzymes of the sucrose to starch pathway in wheat. Plant Growth Regulation 35:81-91 DOI 10.1023/A:1013827600528.

Awad W, Byrne PF, Reid SD, Comas LH, Haley SD. 2018. Great plains winter wheat varies for root length and diameter under drought stress. Agronomy journal 110:226-235 DOI 10.2134/agronj2017.07.0377.

Barnabás B, Jäger K, Fehér A. 2008. The effect of drought and heat stress on reproductive processes in cereals. Plant Cell \& Environment 31:11-38 DOI 10.1111/j.13653040.2007.01727.x.

Bartlett MK, Klein T, Jansen S, Brendan C, Lawren S. 2016. The correlations and sequence of plant stomatal, hydraulic, and wilting responses to drought. Proceedings of the National Academy of Sciences of the United States of America 113:13098-13103 DOI 10.1073/pnas.1604088113.

Chen X, Yang Y, Ran L, Dong Z, Zhang E, Yu X, Xiong F. 2017. Novel insights into miRNA regulation of storage protein biosynthesis during wheat caryopsis development under drought stress. Frontiers in Plant Science 8:1707 DOI 10.3389/fpls.2017.01707.

Comas LH, Becker SR, Cruz VM, Byrne PF, Dierig DA. 2013. Root traits contributing to plant productivity under drought. Frontiers in Plant Science 4:442 DOI 10.3389/fpls.2013.00442.

Farooq M, Hussain M, Siddique KHM. 2014. Drought stress in wheat during flowering and grain-filling periods. Critical Reviews in Plant Sciences 33:331-349 DOI 10.1080/07352689.2014.875291.

Ge P, Ma C, Wang S, Gao L, Li X, Guo G Ma W, Yan Y. 2012. Comparative proteomic analysis of grain development in two spring wheat varieties under drought stress. Analytical and Bioanalytical Chemistry 402:1297-1313 DOI 10.1007/s00216-011-5532-z.

Peer) reviewing PDF | (2021:06:61867:1:1:NEW 11 Jul 2021) 
318

319

320

321

322

323

324

325

326

327

328

329

330

331

332

333

334

335

336

337

338

339

340

341

342

343

344

345

346

347

348

349

350

351

352

353

354

355

Houshmand S, Arzani A, Maibody SAM, Feizi M. 2005. Evaluation of salt-tolerant genotypes of durum wheat derived from in vitro and field experiments. Field Crops Research 91:345354 DOI 10.1016/j.fcr.2004.08.004.

Kaul R. 2011. Effect of water stress on respiration of wheat. Canadian Journal of Botany 44:623-632 DOI 10.1139/b66-075.

Kimball BA, Morris CF, Pinter PJ, Wall GW, Hunsaker DJ, Adamsen FJ, LaMorte RL, Leavitt SW, Thompson TL, Matthias AD, Brooks TJ. 2001. Elevated $\mathrm{CO}_{2}$, drought and soil nitrogen effects on wheat grain quality. New Phytologist 150:295-303 DOI 10.1046/j.1469-8137.2001.00107.x.

Li F, Chen X, Yu X, Chen M, Lu W, Wu Y, Xiong F. 2020. Novel insights into the effect of drought stress on the development of root and caryopsis in barley. PeerJ 8:e8469 DOI 10.7717 peerj.8469.

Li L, Peng Z, Mao X, Wang J, Chang X, Reynolds M, Jing R. 2019. Genome-wide association study reveals genomic regions controlling root and shoot traits at late growth stages in wheat. Annals of Botany 124:993-1006 DOI 10.1093/aob/mcz041.

Lu H, Wang C, Guo T, Xie Y, Feng W, Li S. 2014. Starch composition and its granules distribution in wheat grains in relation to post-anthesis high temperature and drought stress treatments. Starch/Staerke 66:419-428 DOI 10.1002/star.201300070.

Moore KL, Tosi P, Palmer R, Hawkesford MJ, Grovenor CRM, Shewry PR. 2016. The dynamics of protein body formation in developing wheat grain. Plant Biotechnology Journal 14:1876-1882 DOI 10.1111/pbi.12549.

Morales F, Ancín M, Fakhet D, González-Torralba J, Gámez AL, Seminario A, Soba D, Ben MS, Garriga M, Aranjuelo I. 2020. Photosynthetic metabolism under stressful growth conditions as a bases for crop breeding and yield improvement. Plants 9:88 DOI 10.3390/plants9010088.

Niu X, Hu T, Zhang F, Feng P. 2016. Severity and duration of osmotic stress on partial root system: effects on root hydraulic conductance and root growth. Plant Growth Regulation 79:177-186 DOI 10.1007/s10725-015-0123-1.

Ober ES, Alahmad S, Cockram J, Forestan C, Hickey LT, Kant J, Maccaferri M, Marr E, Milner M, Pinto F, Rambla C, Reynolds M, Salvi S, Sciara G, Snowdon RJ, Thomelin P, Tuberosa R, Uauy C, Voss-Fels KP, Wallington E, Watt M. 2021. Wheat root systems as a breeding target for climate resilience. Theoretical and Applied Genetics 134:1645-1662 DOI 10.1007/s00122-021-03819-w.

Ozturk A, Aydin F. 2004. Effect of water stress at various growth stages on some quality characteristics of winter wheat. Journal of Agronomy \& Crop Science 190:93-99 DOI 10.1046/j.1439-037X.2003.00080.x.

Rellán-Álvarez R, Lobet G, Dinneny JR. 2016. Environmental control of root system biology. Annual Review of Plant Biology 67:619-642 DOI 10.1146/annurev-arplant-043015-111848. 
356

357

358

359

360

361

362

363

364

365

366

367

368

369

370

371

372

373

374

375

376

377

378

379

380

381

382

383

384

385

Seung D, Smith AM. 2019. Starch granule initiation and morphogenesis - progress in Arabidopsis and cereals. Journal of Experimental Botany 70:771-784 DOI 10.1093/jxb/ery412.

Thorsten K, Wieland F. 2011. Water uptake by seminal and adventitious roots in relation to whole-plant water flow in barley (Hordeum vulgare L.). Journal of Experimental Botany 62:717733 DOI 10.1093/jxb/erq312.

Vadez V. 2014. Root hydraulics: the forgotten side of roots in drought adaptation. Field Crops Research 165:15-24 DOI 10.1016/j.fcr.2014.03.017.

Végh KR. 1991. Effect of soil water and nutrient supply on root characteristics and nutrient uptake of plants. Developments in Agricultural \& Managed Forest Ecology 24:143-148 DOI 10.1016/B978-0-444-89104-4.50024-4.

Xie Q, Fernando KMC, Mayes S, Sparkes DL. 2017. Identifying seedling root architectural traits associated with yield and yield components in wheat. Annals of Botany 119:11151129 DOI 10.1093/aob/mcx001.

Xue Q, Zhu Z, Musick JT, Stewart BA, Dusek DA. 2003. Root growth and water uptake in winter wheat under deficit irrigation. Plant \& Soil 257:151-161 DOI 10.1023/A:1026230527597.

Yang J, Zhang J. 2006. Grain filling of cereals under soil drying. New Phytologist 169:223-236 DOI 10.1111/j.1469-8137.2005.01597.x.

Yang J, Zhang J, Wang Z, Zhu X. 2004. Activities of key enzymes in sucrose-to-starch conversion in wheat grains subjected to water deficit during grain filling. Plant Physiology 135:1621-1629 DOI 10.2307/4356519.

Yu X, Chen X, Zhou L, Zhang J, Yu H, Shao S, Xiong F, Wang Z. 2015. Structural development of wheat nutrient transfer tissues and their relationships with filial tissues development. Protoplasma 252:605-617 DOI 10.1007/s00709-014-0706-0.

Yu X, Li B, Wang L, Chen X, Wang W, Gu Y, Wang Z, Xiong F. 2015. Effect of drought stress on the development of endosperm starch granules and the composition and physicochemical properties of starches from soft and hard wheat. Journal of the Science of Food \& Agriculture 96:2746-2754 DOI 10.1002/jsfa.7439. 


\section{Table 1 (on next page)}

Plant morphology indexes and spike traits of wheat under drought stress. 


\begin{tabular}{|c|c|c|c|c|c|c|c|c|c|c|}
\hline $\begin{array}{c}\text { Cultiv } \\
\text { ars }\end{array}$ & $\begin{array}{l}\text { Treat } \\
\text { ment }\end{array}$ & $\begin{array}{c}\text { Root length } \\
\text { (cm) }\end{array}$ & $\begin{array}{c}\text { Plant height } \\
\text { (cm) }\end{array}$ & $\begin{array}{l}\text { Dry weight } \\
\text { of roots (g) }\end{array}$ & $\begin{array}{c}\text { Dry weight of } \\
\text { aboveground } \\
\text { parts (g) }\end{array}$ & $\begin{array}{c}\text { Root-shoot } \\
\text { ratio }\end{array}$ & $\begin{array}{c}\text { Spike length } \\
\text { (cm) }\end{array}$ & $\begin{array}{c}\text { Spike weight } \\
\text { (g) }\end{array}$ & $\begin{array}{c}\text { Grains number } \\
\text { per spike }\end{array}$ & $\begin{array}{c}\text { 1000-grains } \\
\text { weight (g) }\end{array}$ \\
\hline \multirow{2}{*}{ YM13 } & $\mathrm{CC}$ & $36.93 \pm 1.77 \mathrm{a}$ & $63.77 \pm 0.83 a$ & $3.47 \pm 0.47 \mathrm{a}$ & $10.27 \pm 0.92 \mathrm{a}$ & $0.34 \pm 0.08 \mathrm{~b}$ & $8.14 \pm 0.37 \mathrm{a}$ & $2.48 \pm 0.11 \mathrm{a}$ & $37.67 \pm 1.99 \mathrm{a}$ & $36.80 \pm 5.19 a$ \\
\hline & DS & $31.93 \pm 1.28 b$ & $60.27 \pm 1.41 b$ & $2.81 \pm 0.45 b$ & $7.09 \pm 1.04 \mathrm{~b}$ & $0.40 \pm 0.03 \mathrm{a}$ & $7.06 \pm 0.32 b$ & $1.67 \pm 0.10 \mathrm{~b}$ & $34.83 \pm 2.59 b$ & $33.22 \pm 4.06 \mathrm{~b}$ \\
\hline \multirow{2}{*}{ YN19 } & $\mathrm{CC}$ & $28.27 \pm 1.65 \mathrm{c}$ & $56.23 \pm 1.84 \mathrm{c}$ & $2.45 \pm 0.53 b$ & $6.85 \pm 0.55 \mathrm{c}$ & $0.36 \pm 0.06 \mathrm{~b}$ & $7.31 \pm 0.16 b$ & $1.68 \pm 0.17 b$ & $30.56 \pm 1.57 \mathrm{c}$ & $33.41 \pm 0.85 b$ \\
\hline & DS & $25.70 \pm 1.84 \mathrm{~d}$ & $54.67 \pm 1.59 \mathrm{c}$ & $1.52 \pm 0.42 \mathrm{c}$ & $3.85 \pm 0.04 \mathrm{~d}$ & $0.39 \pm 0.10 \mathrm{a}$ & $6.36 \pm 0.06 c$ & $1.04 \pm 0.05 \mathrm{c}$ & $27.17 \pm 1.54 \mathrm{~d}$ & $31.70 \pm 1.61 \mathrm{c}$ \\
\hline
\end{tabular}

1 Data are shown as mean \pm standard deviation, $\mathrm{n}=6$. Different lowercase in the same column

2 indicate significant difference $(\mathrm{p}<0.05)$. CC, control condition; DS, drought stress. 
Table 2 (on next page)

Correlation coefficients between traits of roots and aboveground parts in wheat under drought stress. 


\begin{tabular}{cccccccc}
\hline Indexes & & $\begin{array}{c}\text { Plant } \\
\text { height }\end{array}$ & $\begin{array}{c}\text { Dry weight of } \\
\text { aboveground } \\
\text { parts }\end{array}$ & $\begin{array}{c}\text { Spike } \\
\text { weight }\end{array}$ & $\begin{array}{c}\text { 1000-grains } \\
\text { weight }\end{array}$ & $\begin{array}{c}\text { Relative area of } \\
\text { amyloplast }\end{array}$ & $\begin{array}{c}\text { Relative area } \\
\text { of protein } \\
\text { body }\end{array}$ \\
\hline \multirow{2}{*}{ Root length } & CC & $-0.78^{*}$ & -0.33 & 0.37 & -0.54 & 0.51 & $0.70^{*}$ \\
& DS & -0.14 & -0.57 & 0.67 & -0.45 & $0.79^{*}$ & $0.78^{*}$ \\
Dry weight & CC & $0.85^{*}$ & $0.99^{*}$ & 0.48 & $0.58^{*}$ & 0.41 & -0.22 \\
of roots & DS & $0.89^{*}$ & $0.98^{*}$ & 0.29 & 0.19 & 0.29 & -0.03 \\
Root-shoot & CC & -0.43 & $-0.74^{*}$ & $-0.61^{*}$ & 0.27 & $-0.85^{*}$ & -0.58 \\
ratio & DS & -0.15 & -0.39 & -0.33 & 0.57 & $-0.86^{*}$ & $-0.75^{*}$ \\
\hline
\end{tabular}

1 Each correlation coefficient is calculated from six values. Asterisks in the upper right corner of the

2 number indicate that the correlation coefficient is significant $(\mathrm{p}<0.05)$. CC, control condition;

3 DS, drought stress. 


\section{Figure 1}

Morphology and structure of wheat roots under drought stress.

(A) Morphology of wheat roots. (B-C) Microstructure of YM13 root cross section under control condition and drought stress. (D-E) Microstructure of YN19 root cross section under control condition and drought stress. CC, control condition; Co, cortex; DS, drought stress; Ph, phloem; VC, vascular cylinder; XV, xylem vessel. Scale bars: (A) $8 \mathrm{~cm},(B-E) 50 \mu \mathrm{m}$.
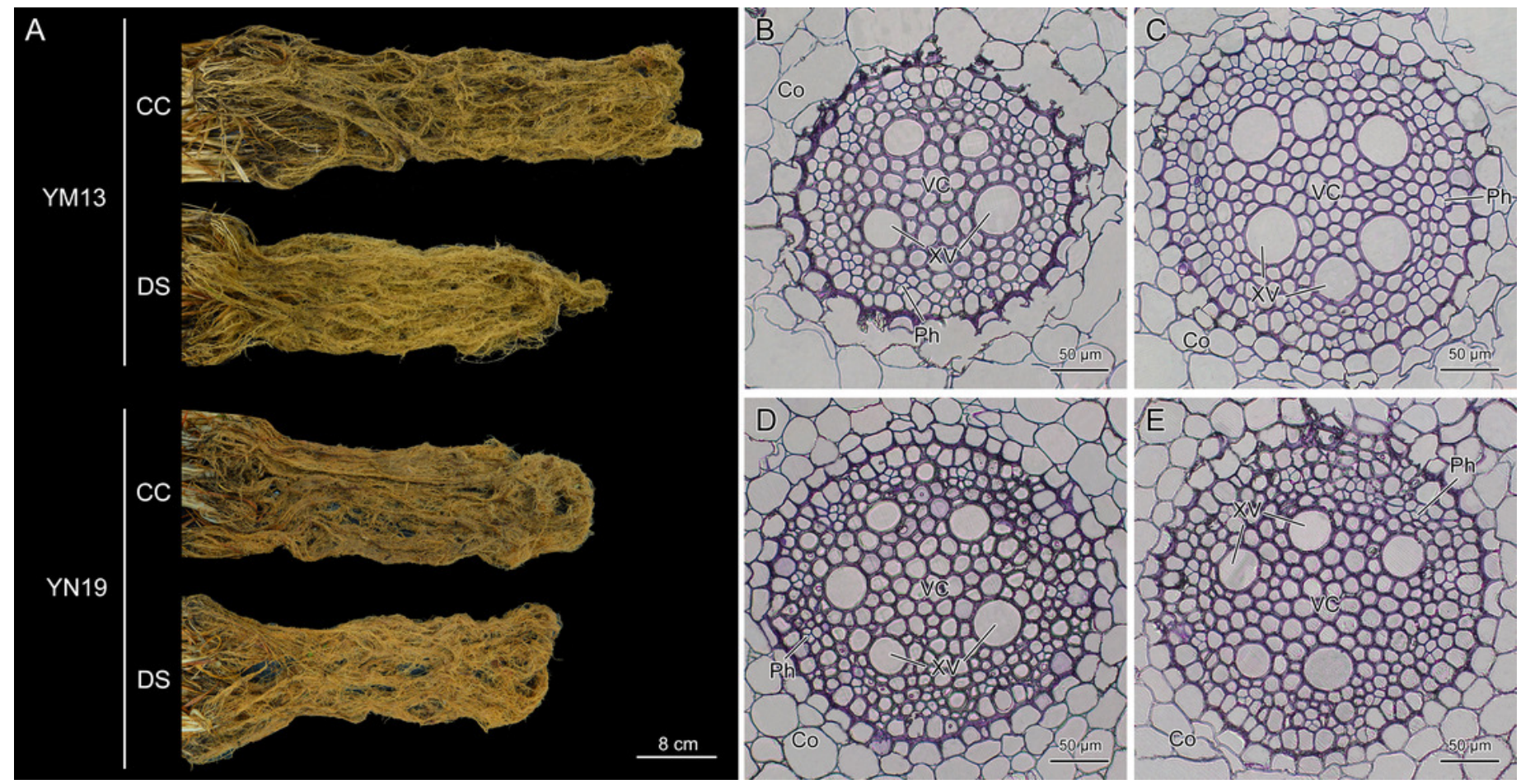


\section{Figure 2}

Changes in caryopsis weight and endosperm enrichment in wheat under drought stress.

(A) Fresh weight of caryopses. (B) Dry weight of caryopses. (C) Ratio of amyloplast area to endosperm area. (D) Ratio of protein body area to endosperm area. CC, control condition; DS, drought stress. Different lowercase above the histogram indicate significant difference ( $p$ $<0.05)$.

A
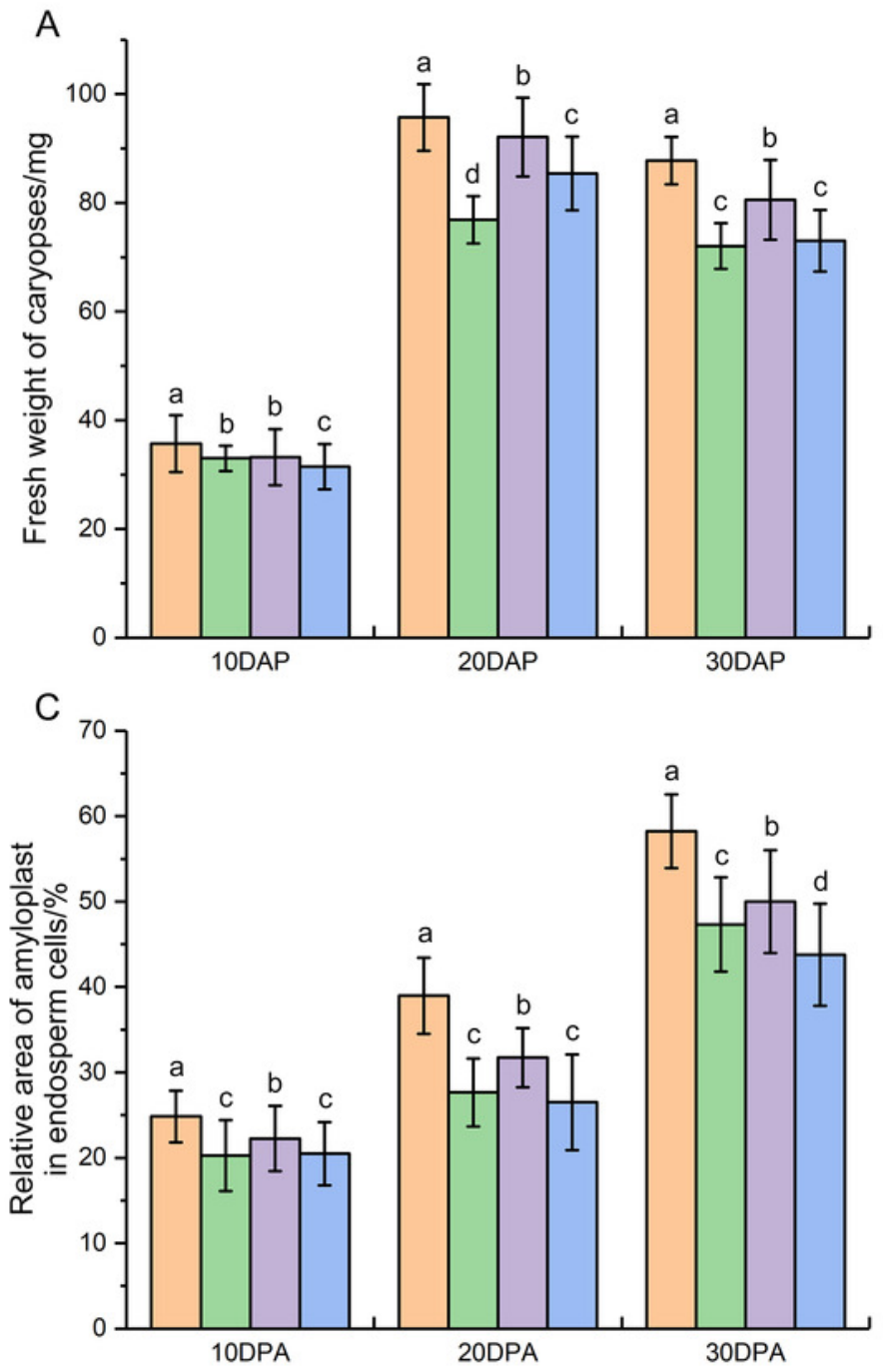

B
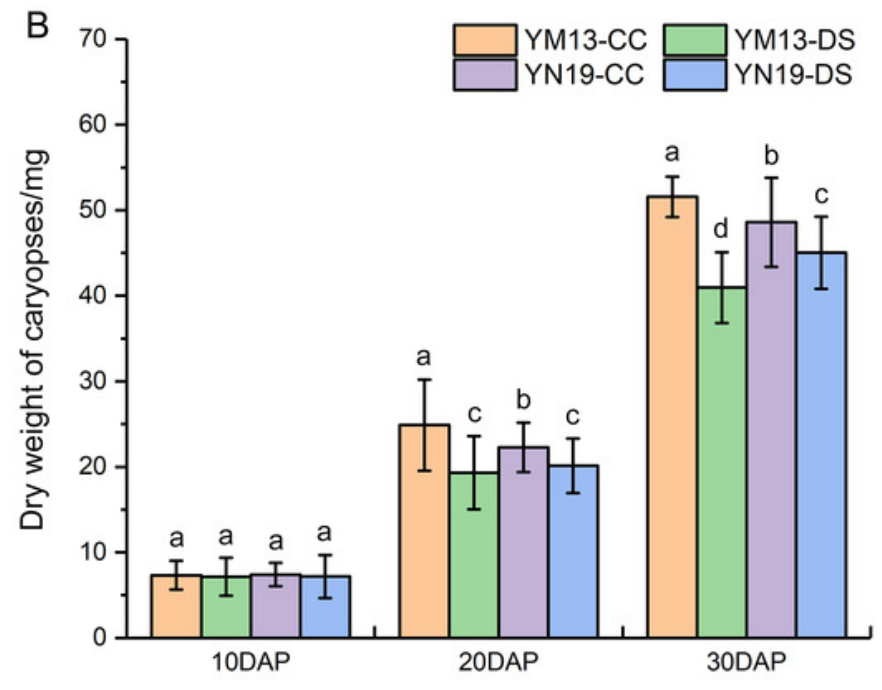

D

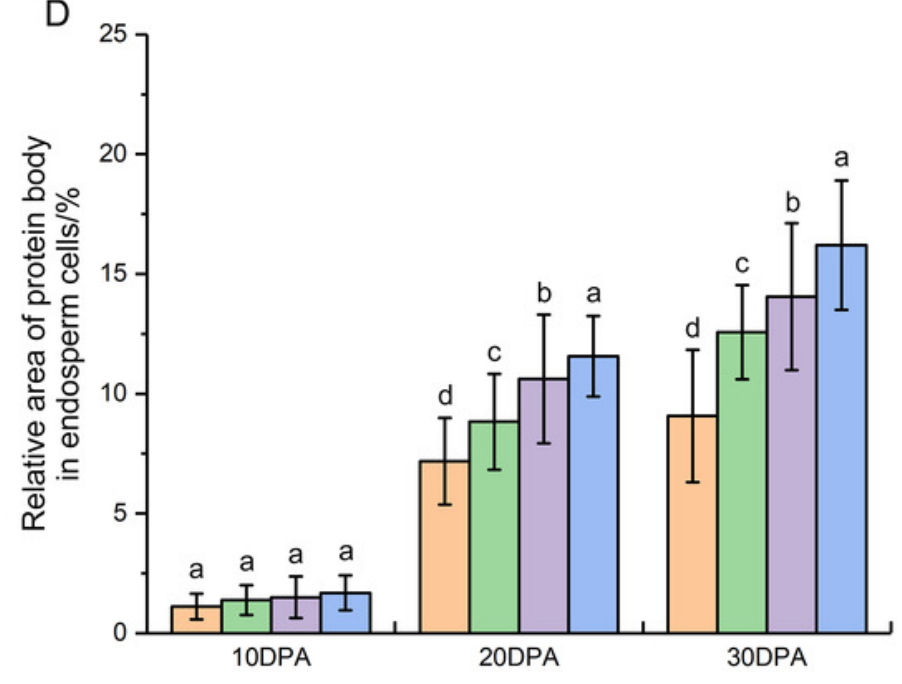




\section{Figure 3}

Microstructure of endosperm in wheat caryopses under drought stress.

(A-D) Microstructure of endosperm at 10 DPA. (E-H) Microstructure of endosperm at 20 DPA. (I-L) Microstructure of endosperm at 30 DPA. Am, amyloplast; CC, control condition; DS, drought stress; PB, protein body. Scale bars: $40 \mu \mathrm{m}$.

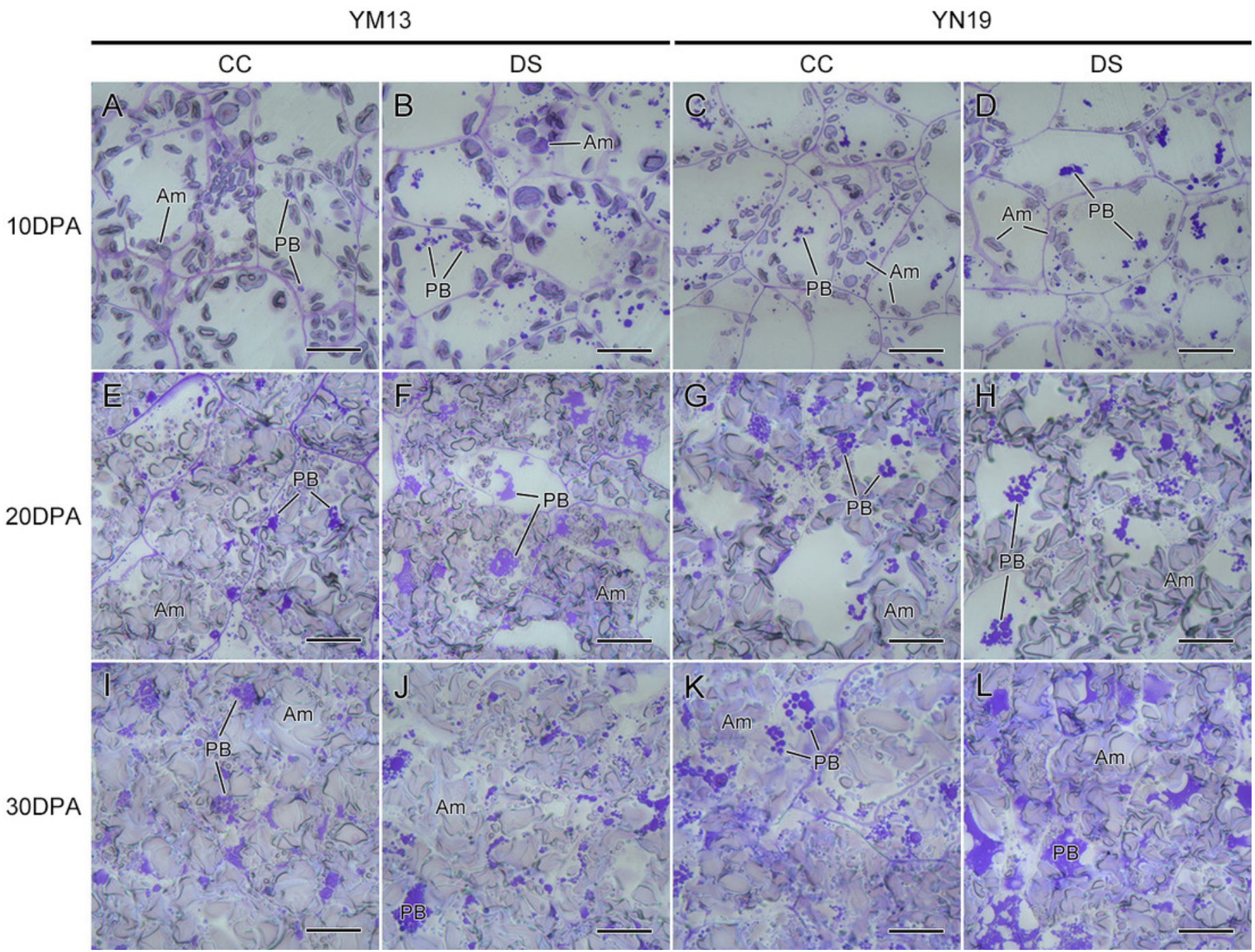

